[Agr. Biol. Chem., Vol. 36, No. 2, p. 305 312, 1972]

\title{
Studies on the Mechanism of Activation of Pepsinogen
}

\author{
Part II. Effects of Substrate and Competitive Inhibitor \\ on the Activation of Pepsinogen
}

\author{
By Masaru Funatsu, Yoshitada Harada, Katsuya Hayashi \\ and Takeo KANEDA \\ Laboratory of Biochemistry, Faculty of Agriculture, Kyushu University, \\ Fukwoka, Japan
}

Received September 3, 1971

\begin{abstract}
Experiments were carried out on the effects of substrate or competitive inhibitor on the rate of appearance of N-terminal isoleucine residue of pepsin and peptides released from pepsinogen in its conversion to pepsin. Assumptions were made from these experiments, that an active site is initially formed in pepsinogen by acidification of its solution, and that peptide bond between $4 \mathrm{l}$-glutamyl and 42 -isoleucyl residues locates in the juxtaposition to the active site forming an intramolecular enzyme-substrate complex. Thus, N-terminal tail of pepsinogen is released by a hydrolysis catalyzed by its own active site,

It was indeed ascertained in this study that neither a small amount of pepsin which could be accompanied by pepsinogen preparation used contributes to the initial step of hydrolysis of pepsinogen nor pepsin formed accelerates the following activation process.

Therefore, it was concluded that the conversion of pepsinogen to pepsin is self-degradation process.
\end{abstract}

In the preceding paper, ${ }^{17}$ the possibility was suggested that active site initially formed in pepsinogen in consequence of a specific conformational change in acid solution catalyzes the hydrolysis of peptide bond between 41glutamic acid residue and 42-isoleucine residue which becomes N-terminal of pepsin.

Prior to verify this assumption, there was a question to be examined that a small amount of pepsin which could be accompanied by pepsinogen preparation used might catalyze the initial step of hydrolysis of peptide bond in acid solution producing pepsin, which subsequently promotes the conversion of pepsinogen to pepsin.

However, it was ascertained that pepsin was involved in neither the initial step of limited proteolysis nor the following activation of pepsinogen.

Thus, attempts were made to examine whether active site is formed or not in pepsinogen by acidification. Namely, based on an assumption that only substrate or competitive inhibitor could detect the formation of active site in pepsinogen, the effects of carbobenzoxy-L-glutamyl-L-phenylalanine as a substrate and isoamyl alcohol as a competitive inhibitor on the rate of appearance of $\mathrm{N}$ terminal isoleucine residue of pepsin and the pattern of peptides released from pepsinogen in the process of its activation were studied.

As the results, the appropriateness of the mechanism of activation above assumed was accepted.

Recently, during the preparation of manuscript of the present paper Bustin and ConwayJacobs $^{21}$ reported the same mechanism of activation of porcine pepsinogen as will be discussed in this paper. However, their assumption was obtained by experiments per- 
formed according to different points of view from ours.

\section{MATERIALS AND METHODS}

Pepsinogen preparation. Pepsinogen was prepared as previously described.1 It was dialyzed against $0.1 \mathrm{M}$ ammonium bicarbonate, $\mathrm{pH} 8.1$ for 3 days and lyophilized.

Substrate. Casein was purchased from Merck, Co., Ltd. Hemoglobin was prepared by Heidelberger's method. 3) Carbobenzoxy-L-glutamyl-L-phenylalanine (Cbz-glu-phe)" employed to study the effect of substrate on the activation of pepsinogen was purchased from Protein Research Foundation, Osaka.

Competitive inhibitor. Isoamyl alcohol ${ }^{5,6}$ was employed.

Measurement of peptic activity. Pectic activity was measured at $\mathrm{pH} 1.8$ by routine method using either casein or hemoglobin as a substrate. The activity was represented as the value of O.D. at $275 \mathrm{~m} ! !$ of the supernatant obtained by removing precipitate produced by addition of trichloroacetic acid solution to the reaction mixture.

Measurement of rate of activation in the presence of isoamyl alcohol as competitive inhibitor. Pepsinogen dissolved in $0.1 \mathrm{M}$ phosphate buffer, $\mathrm{pH} 6.9$, was mixed with isoamyl alcohol; the final concentration of pepsinogen was 0.04 per cent. The pepsinogen was activated at $\mathrm{pH} 2.5$ and $15^{\circ} \mathrm{C}$ by adding $0.3 \mathrm{~N} \mathrm{HCl}$. At a certain interval of time, $1 \mathrm{ml}$ of the activation mixture was taken and added to $2 \mathrm{ml}$ of $0.60^{\circ}$ hemoglobin solution, $\mathrm{pH} 1.8$, and subsequently was incubated at $15^{\circ} \mathrm{C}$ for $1 \mathrm{~min}$. Immediately after the incubation, $2 \mathrm{ml}$ of $0.44 \mathrm{M}$ trichloroacetic acid were added to the reaction mixture. The value of O.D. at $275 \mathrm{~m}$ " of the filtrate was measured.

The analyses of $N$-terminal amino acid produced in the process of activation of pepsinogen in the presence and absence of $\mathrm{Cb}-$-glu-phe, as substrate. The activation of pepsinogen was carried out either in the presence or absence of Cbz-glu-phe as described below, and the rate of appearance of new $\mathrm{N}$-terminal isoleucine due to the conversion of pepsinogen to pepsin in the presence of about 100 molar excess of substrate per mole pepsinogen was compared with that in the absence of substrate.
A) The activation of pepsinogen in the absence of substrate. Pepsinogen solution was prepared dissolv. ing $700 \mathrm{mg}$ of pepsinogen in $15 \mathrm{ml}$ of $0.001 \mathrm{M}$ phosphate buffer, pH 7.25, and each $2 \mathrm{ml}$ aliquot of the solution was taken into test tube separately and left at $5^{\circ} \mathrm{C}$ for $30 \mathrm{~min}$. Except a test tube for blank test, each $0.1 \mathrm{ml}$ of $0.3 \mathrm{~N} \mathrm{HCl}$ was added to the tubes to yield a $\mathrm{pH} 4.3$ and the tubes were incubated at $5^{\circ} \mathrm{C}$ for $5,10,20,30$ and $60 \mathrm{~min}$, respectively. One hundred $\mathrm{mg}$ of sodium bicarbonate and $4 \mathrm{ml}$ of $50^{\circ}(\mathrm{v} / \mathrm{v})$ FDNBethanol solution were added to each tube immediately after the incubation of a given time. Dinitrophenylation was performed at $25^{\circ} \mathrm{C}$ for $2 \mathrm{hr}$. The reaction mixture was centrifuged and the precipitate was washed five times with each $5 \mathrm{ml}$ of ethanol, of acetone and of ether, successively. After drying the precipitate in desiccator in vacuo, $2 \mathrm{ml}$ of $6 \mathrm{~N} \mathrm{HCl}$ were added to the dry material and hydrolyzed at $108^{\circ} \mathrm{C}$ for $16 \mathrm{hr}$ in a sealed tube. The hydrolysate was extracted with ether, and DNP-amino acids contained in the ether layer were analyzed in the same manner as described in the previous paper."

B) The activation of pepsinogen in the presence of substrate. Each $2 \mathrm{ml}$ aliquot of the same pepsinogen solution as described above (ca. 2 pmoles of pepsinogen) was added separately to test tube containing 200 umoles substrate per tube. To adjust the mixture to $\mathrm{pH} 4.3,0.08 \mathrm{ml}$ of $0.3 \mathrm{~N} \mathrm{HCl}$ was required. Incubation was carried out at $\mathrm{pH} 4.3$ and $5^{\circ} \mathrm{C}$ for 5,10 , 20,30 and $60 \mathrm{~min}$, respectively. To the reaction mixture $100 \mathrm{mg}$ of sodium bicarbonate and $4 \mathrm{ml}$ of $5 \%$ FDNB-ethanol solution were added immediately after activation of a given time. The subsequent procedure of analysis of DNP-amino acid was the same as described in the section $A$.

The analyses of $N$-terminal amino acid appeared in the process of activation of pepsinogen in the presence and absence of competitive inhibitor. Pepsinogen solution employed was prepared dissolving $300 \mathrm{mg}$ of pepsinogen in $6.5 \mathrm{ml}$ of $0.1 \mathrm{M}$ phosphate buffer, $\mathrm{pH} 7.0$.

The final concentration of competitive inhibitor, isoamyl alcohol, added to the pepsinogen solution was 2.68 per cent, i.e., about 400 moles per mole of pepsinogen. Similar to the substrate mentioned above, comparisons were made of the rate of appearance of $\mathrm{N}$-terminal isoleucine on the activations of pepsinogen at $\mathrm{pH} 4.3$ and $5^{\circ} \mathrm{C}$ for $5 \mathrm{~min}$ as well as $2 \mathrm{hr}$ in the presence of isoamyl alcohol with those in the absence of the alcohol, respectively. 
C) The activation of pepsinogen in the absence of isoamyl alcohol. The pepsinogen solution was adjusted to $\mathrm{pH} 4.3$ by adding $0.06 \mathrm{ml}$ of $2 \mathrm{~N} \mathrm{HCl}$ to $2 \mathrm{ml}$ of the solution.

D) The activation of pepsinogen in the presence of isoamyl alcohol. To $2 \mathrm{ml}$ of the pepsinogen solution $0.05 \mathrm{ml}$ of isoamyl alcohol and then $0.06 \mathrm{ml}$ of $2 \mathrm{~N}$ $\mathrm{HCl}$ were added. The $\mathrm{pH}$ of the solution was 4.3 .

E) The quantitative analysis of the $N$-terminal amino acid. The pepsinogen solution described in the above $\mathrm{C}$ and $\mathrm{D}$ sections was incubated at $5^{\circ} \mathrm{C}$ for $5 \mathrm{~min}$ and for $2 \mathrm{hr}$. Immediately after the incubations of given times, $80 \mathrm{mg}$ of sodium bicarbonate and $4 \mathrm{ml}$ of $5 \%$ FDNB-ethanol solution were added and dinitrophenylation was performed at $30^{\circ} \mathrm{C}$ for $2 \mathrm{hr}$. After the incubation, $1 \mathrm{ml}$ of ethanol $\left(99.9^{\circ}\right), 0.5 \mathrm{ml}$ of 660 ethanol-0.001 M phosphate buffer (pH 7.25) mix. ture and $1 \mathrm{ml}$ of $2 \mathrm{~N} \mathrm{HCl}$ were added, where the suspension was ca. pH 2 after stirring, the suspension was centrifuged and separated into precipitate and supernatant fractions.

The precipitate fraction was four times centrifuged by adding $5 \mathrm{ml}$ of $60^{\circ}$ o ethanol-0.001 $\mathrm{M}$ phosphate buffer ( $\mathrm{pH} 7.25$ ) mixture and $0.5 \mathrm{ml}$ of $2 \mathrm{NHCl}$. The washings were combined with supernatant fraction. The precipitate was again washed with ether and dried in desiccator in vacuo. The dry material was hydrolyzed in a sealed tube with $2 \mathrm{ml}$ of $6 \mathrm{~N}$ $\mathrm{HCl}$ at $108^{\circ} \mathrm{C}$ for $18 \mathrm{hr}$. The hydrolysate was extracted with ether. The ether-layer was evaporated to dryness and the residue obtained was hydrolyzed with $2 \mathrm{ml}$ of saturated barium hydroxide solution at $108^{\circ} \mathrm{C}$ for $3 \mathrm{hr}$ in a sealed tube. The subsequent procedure for the determination of $\mathrm{N}$-terminal amino acid was the same as described in the previous paper. ${ }^{1}$

The supernatant fraction combined with the washing was concentrated to about $4 \mathrm{ml}$ by warm air stream to remove alcohol, and then neutralized by adding 1 to $2 \mathrm{ml}$ of $2 \mathrm{~N} \mathrm{NaOH}$, where the suspension was at about $\mathrm{pH} 7$. After excess of FDNB was extracted with ether, $1 \mathrm{ml}$ of $2 \mathrm{~N} \mathrm{HCl}$ was added and acidified to about pH2. The acidic solution was extracted with ether.

The ether-layer was evaporated to dryness and the resulted residue was hydrolyzed in $2 \mathrm{ml}$ of saturated barium hydroxide solution at $108^{\circ} \mathrm{C}$ for $3 \mathrm{hr}$ in a sealed tube. The procedure for the determination of amino acid regenerated was the same as described in the previous paper. ${ }^{1}$
The water-layer was concentrated to about $1 \mathrm{ml}$ and applied onto a talc column $(1.5 \times 2 \mathrm{~cm})$ equilibrated with $1 \mathrm{~N} \mathrm{HCl}$ to remove salts. DNP-peptides were eluted with acetic acid-ethanol ( $11, v / v) \mathrm{mix}$ ture. About $15 \mathrm{ml}$ of effuent were collected and evaporated to dryness and subsequently it was hydrolyzed in $20 \mathrm{ml}$ of saturated barium hydroxide at $108^{\circ} \mathrm{C}$ for $3 \mathrm{hr}$. DNP-amino acids were determined by the same method as described in the previous paper."

The preparation of peptide fraction formed in the process of activation of pepsinogen in the presence and absence of isoamyl alcohol. Pepsinogen solution employed in this experiment was prepared dissolving $810 \mathrm{mg}$ of pepsinogen in $20 \mathrm{ml}$ of $0.1 \mathrm{M}$ phosphate buffer, $\mathrm{pH} 7.0$. The activation of pepsinogen was performed at $\mathrm{pH} 4.3$ and $5^{\circ} \mathrm{C}$ for $2 \mathrm{hr}$. To adjust the solution to $\mathrm{pH} 4.3$, $0.55 \mathrm{ml}$ of $2 \mathrm{~N} \mathrm{HCl}$ was required. The activation was stopped by adding $\mathrm{lg}$ of sodium bicarbonate, and the neutralized reaction mixture was applied onto a column of SE-Sephadex C-25 $(3 \times 18 \mathrm{~cm})$ equilibrated with $0.2 \mathrm{M}$ volatile acetate buffer, $\mathrm{pH} 6.0$. Rajagopalan et al. ${ }^{7}$ used the same column chromato. graphy at $\mathrm{pH} 4.4$ and $4^{\circ} \mathrm{C}$ to restrain the autolysis of pepsin. In the present experiments, however, the similar chromatography was used at pH 6.0 and room temperature to separate peptides released from pepsinogen. The peptide fraction eluted after protein fraction was collected and evaporated to dryness by rotary evaporator. The dry material obtained was dissolved with $2 \mathrm{ml}$ of deionized water. An aliquot of $0.1 \mathrm{ml}$ of the solution was used for amino acid analysis and the remaining $1.9 \mathrm{ml}$ for the determina tion of N-terminal amino acid.

F) The activation of pepsinogen in the absence of isoamyl alcohol. Procedures of activation of pepsinogen and separation of peptides produced were the same as mentioned above.

G) The activation of pepsinagen in the presence of isoamyl alcohol. To the pepsinogen solution mentioned above $0.54 \mathrm{ml}$ of isoamyl alcohol was added and the solution was adjusted to $\mathrm{pH} 4.3$. The subsequent procedures of activation of pepsinogen and separation of peptides produced were the same as described above.

Amino acid analysis of the peptide fraction. One tenth $\mathrm{ml}$ of the peptide solution obtained from the $G$ and/or $F$ as mentioned above was evaporated to dryness and hydrolyzed in $2 \mathrm{ml}$ of $6 \mathrm{~N} \mathrm{HCl}$ at $108^{\circ} \mathrm{C}$ 
for $24 \mathrm{hr}$. The amino acid composition of the whole peptide fraction was analyzed by amino acid analyzer, Hitachi Model KLA 3B.

$N$-Terminal amino acid analysis of the peptide fraction. To $1.9 \mathrm{ml}$ of the peptide solution obtained from the procedures described in sections $\mathrm{G}$ and $\mathrm{F}, 4 \mathrm{ml}$ of $5 \%$ FDNB-ethanol solution and $50 \mathrm{mg}$ of sodium bicarbonate were added and the dinitrophenylation was carried out overnight at room temperature with stirring. The subsequent procedure was the same as mentioned in the section $E$.

\section{RESULTS}

The effect of isoamyl alcohol on the time course of activation of pepsinogen

The Fig. 1 shows the time course of activation of pepsinogen in the presence and absence of isoamyl alcohol. It was found that the time required for attaining the maximum peptic activity was the same, i.e. $6 \mathrm{~min}$ after beginning of activation, regardless of the presence and absence of isoamyl alcohol.

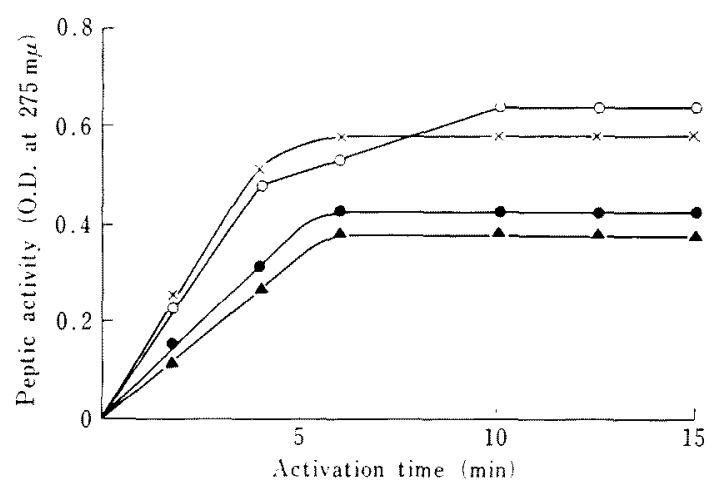

FIG. 1. Effect of Isoamyl Alcohol on the Rate of Activation of Pepsinogen.

The following signs show the concentration of isoamyl alcohol: $\Delta-\mathbf{\Delta} 2.5 \%, 0-25 \%$, $x-x$ $0.63 \%, 0-00 \%$.

The rate of appearance of $N$-terminal amino acid in the process of activation of pepsinogen in the presence and absence of substrate

The Fig. 2 shows the time course of $\mathrm{N}$ -

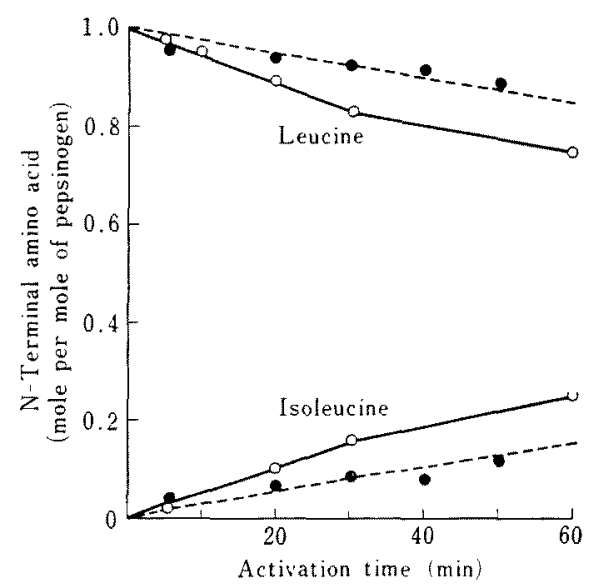

FIG. 2. The Rate of Appearance and Disappearance of N-Terminal Amino Acid of Protein Fraction in the Process of Activation of Pepsinogen in the Presence and Absence of Substrate at $\mathrm{pH} 4.3$ and $5^{\circ} \mathrm{C}$.

The solid line $(0-0)$ shows the time course of change in quantities of N-terminal leucine and isoleucine in the absence of substrate, while the dotted line (-) shows that in the presence of about 100 molar excess of substrate per mole of pepsinogen.

terminal leucine and isoleucine appeared in the process of activation of pepsinogen by acidification in the presence and absence of substrate, Cbz-glu-phe. Leucine is the Nterminus of pepsinogen which is not yet subjected to self-degradation, and isoleucine is that of pepsin produced from pepsinogen by acidification.

It was evidenced that the rate of appearance of N-terminal isoleucine from pepsinogen in the presence of substrate was by 40 per cent slower than that in the absence of substrate.

The amounts of DNP-amino acids obtained from pepsinogen solution activated in the presence and absence of competitive inhibitor

The Fig. 3 shows the quantities of DNPamino acids obtained from the pepsinogen solution incubated at $\mathrm{pH} 4.3$ and $5^{\circ} \mathrm{C}$ for $2 \mathrm{hr}$ in the presence and absence of competitive 


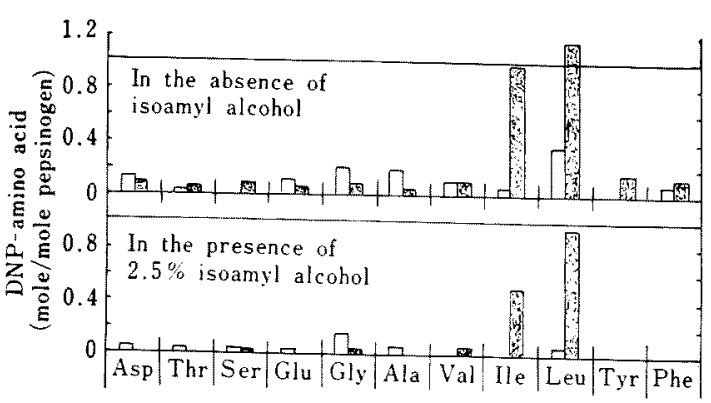

FIG. 3. The Quantities of DNP-Amino Acids Obtained from Pepsinogen Solution Activated at $\mathrm{pH}$ 4.3 and $5^{\circ} \mathrm{C}$ for $2 \mathrm{hr}$ in the Presence and Absence of Isoamyl Alcohol.

The molar amounts of DNP-amino acids were calculated assuming the molar amount of DNP. leucine in the absence of isoamyl alcohol to be 1.0.

- $\square$ indicate DNP-amino acid obtained from protein fraction and free amino acid fraction, respectively.

inhibitor, isoamyl alcohol.

As shown in Fig. 3, it was revealed that on the activation for $2 \mathrm{hr}$ the molar ratio of isoleucine to leucine was 56.2 to 100 in the presence of isoamyl alcohol, while it was 88.4 to 100 in the absence of alcohol. On the other hand, on the activation for $5 \mathrm{~min}$ the ratio was found to be 2.29 to 100 in the presence of alcohol and 7.58 to 100 in the absence of alcohol. Therefore, the rate of appearance of N-terminal isoleucine was decreased by isoamyl alcohol.

\section{Amino acid analyses of the peptide fractions}

The results of amino acid analyses of the peptide fractions obtained by the experiments mentioned in the above $F$ and $G$ sections are shown in Table I. Since it has been reported that on the activation of pepsinogen $\mathrm{N}$ terminal peptide composed of 41 amino acid residues including nine lysine residues is released from pepsinogen, ${ }^{8 !}$ the molar ratio of amino acids in Table I was calculated assuming mole of lysine to be 9. As the results, the amino acid composition of the whole peptide fraction obtained in the presence of
Table I. Ratios of Amino Acies Contained IN THE Whole Peptide Fraction

Ratios of amino acids were calculated assuming the number of lysine to be 9 .

\begin{tabular}{ccc} 
& \multicolumn{2}{c}{ Ratios of amino acids } \\
Amino acid & $\begin{array}{c}\text { In the absence of } \\
\text { isoamyl alcohol }\end{array}$ & $\begin{array}{c}\text { In the presence of } \\
\text { isoamyl alcohol }\end{array}$ \\
\hline Lys & 9 & 9 \\
Arg & 3 & 3 \\
Asp & 5 & 5 \\
Thr & 3 & 2 \\
Ser & 2 & 3 \\
Glu & 2 & 4 \\
Pro & 3 & - \\
Gly & 2 & 3 \\
Ala & 4 & 4 \\
Val & 1 & 2 \\
Ile & 1 & 2 \\
Leu & 4 & 5 \\
Tyr & 2 & 2 \\
Phe & 2 & 3 \\
\hline
\end{tabular}

“._." not estimated.

isoamyl alcohol was almost identical to that obtained in the absence of the alcohol, except proline.

Comparison of properties of peptide fraction ob tained in the presence of isoamyl alcohol zeitl those obtained in the absence of the alcohol

Table II shows the $\mathrm{N}$-terminal amino acid:

TABLE II. DNP-AMINO ACIDS FOUND IN THE Peptide Fraction Produced in the PRESENCE AND ABSENCE OF ISOAMYL ALCOHOL

Ratios of residues were calculated assuming leucine obtained in the absence of isoamyl alcohol to be 1.00 .

\begin{tabular}{lcc}
\hline DNP-amino & Molar ratios of residues \\
acid found & - isoamyl alcohol + isoamyl alcohol \\
\hline Ala & 0.20 & \\
Val & 0.16 & 0.02 \\
Ile & 1.21 & 0.02 \\
Leu & 1.00 & \\
Phe & 0.19 &
\end{tabular}


of peptide fraction obtained by procedures described in the above sections, F and G.

Obviously from Table II, several kinds of DNP-amino acid which were derived from N-terminal amino acid residues of peptides were obtained in the absence of isoamyl alcohol as compared with those obtained in the presence of the alcohol.

\section{DISCUSSION}

Prior to verify the assumption that a certain conformational change in pepsinogen in acid solution involved the formation of active site which catalyzes the release of peptides from the same molecule producing pepsin, it seemed indispensable to exclude the possibilities that a small amount of pepsin accompanied by pepsinogen preparation employed catalyzes the initial step of limited hydrolysis of peptide bond, and that pepsin produced subsequently promotes the following conversion of pepsinogen to pepsin.

However, the pepsinogen preparation was obtained by dialysis against $0.1 \mathrm{M}$ ammonium bicarbonate solution, $\mathrm{pH} 8.1$, for 3 days and lyophilization, and such an alkali-treatment should consequently inactivate pepsin completely and irreversibly, even if the pepsinogen was contaminated by pepsin. In addition a fact that a treatment of pepsinogen preparation with borate buffer of $\mathrm{pH} 8.0$ at $35^{\circ} \mathrm{C}$ for $15 \mathrm{~min}$ before it was activated by acidification did not affect the rate of appearance of peptic activity led to the following conclusion, i.e., the pepsinogen preparation employed throughout this study was free from pepsin, hence the participation of pepsin in the initial step of activation can be obviously excluded.

The possibility that pepsin produced might accelerate the conversion of pepsinogen to pepsin was also refused by an experiment concerning the effect of isoamyl alcohol on the rate of production of pepsin.

If pepsin promotes the activation of the remaining pepsinogen, the time required for attaining the maximum peptic activity of the solution should be delayed by the inhibitory action of isoamyl alcohol. However, obviously from Fig. 1, the peptic activity has reached to the maxinum value independently of the presence of isoamyl alcohol.

Consequently, both possibilities as to the contribution of pepsin to the activation of pepsinogen was evidently refused.

Supposing this conclusion is correct, attempts were made to ascertain the formation of active site in pepsinogen by acidification.

On the assumption that substrate and/or competitive inhibitor can combine with active site formed in pepsinogen and affect the mode of activation, these compounds were added to the pepsinogen solution prior to acidification.

The addition of substrate, Cbz-glu-phe, caused the decrease in the rate of self-degradation of pepsinogen, hence the rate of appearance of N-terminal isoleucine in acid solution as shown in Fig. 2. From this, it was inferred that substrate can bind to pepsinogen prior to the conversion of pepsinogen to pepsin and inhibits the self-degradation of pepsinogen. In addition, since the binding of substrate to pepsinogen is referred to the existence of active site in pepsinogen, the fact mentioned above appears to indicate the formation of active site in pepsinogen in acid.

Similarly to the substrate, competitive inhibitor, isoamyl alcohol affected the activation of pepsinogen in acid. The self-degradation, hence the appearance of a new terminal isoleucine was restricted by the presence of isoamyl alcohol as can be seen in Fig. 3.

Furthermore, the variety and quantity of peptide released in the process of activation in the presence of isoamyl alcohol diminished as compared with those in the absence of the alcohol.

As shown in Table I, the amino acid composition of the whole peptide fraction was not affected by isoamyl alcohol, while the variety and quantity of DNP-amino acid derived from $\mathrm{N}$-terminus of the peptide fraction was 
affected remarkably as evidenced from Table II. The number of DNP-amino acid detected was diminished in the presence of isoamyl alcohol. These facts indicate that only a small amount of big peptide was released in the presence of the alcohol, while in the absence of the alcohol, a relatively large amount of small peptide which should have derived secondarily from the same big peptide as that produced in the presence of the alcohol was produced. The secondary degradation of the peptide should be affected by isoamyl alcohol.

The evidences mentioned above as to the effect of isoamyl alcohol imply that active site is most likely formed in pepsinogen in consequence of a specific conformational change in acid solution.

On the basis of the experimental results and discussions described in the preceding and the present papers, a hypothesis of the mechanism of activation of pepsinogen was proposed. A schematic diagram for the activation hypothesis is shown in Fig. 4.

The mechanism of activation of pepsinogen is clearly different from that of trypsinogen ${ }^{9}$ and of chymotrypsinogen. ${ }^{10,11}$ In the latter cases, trypsin added to the zymogen solution catalyzes the hydrolysis of peptide bond in zymogen. The formation of active site in the enzyme produced is ascribed to a specific conformational change accompanied by the release of peptide from zymogen.

On the contrary, the first step of activation of pepsinogen begins by forming the active site conformation in pepsinogen accompanied by a specific conformational change by means of acidification. It seems reasonable to postulate that carboxyl group of the active aspartic acid residue, ${ }^{12 \sim 16}$ which interact probably with s-amino group of lysine residue located in N-terminal moiety of pepsinogen by salt-linkage, should be liberated by acidification.

Thus, the active site formed would be exposed on the surface of pepsinogen molecule as schematically shown as $\mathrm{B}$ in Fig. 4.

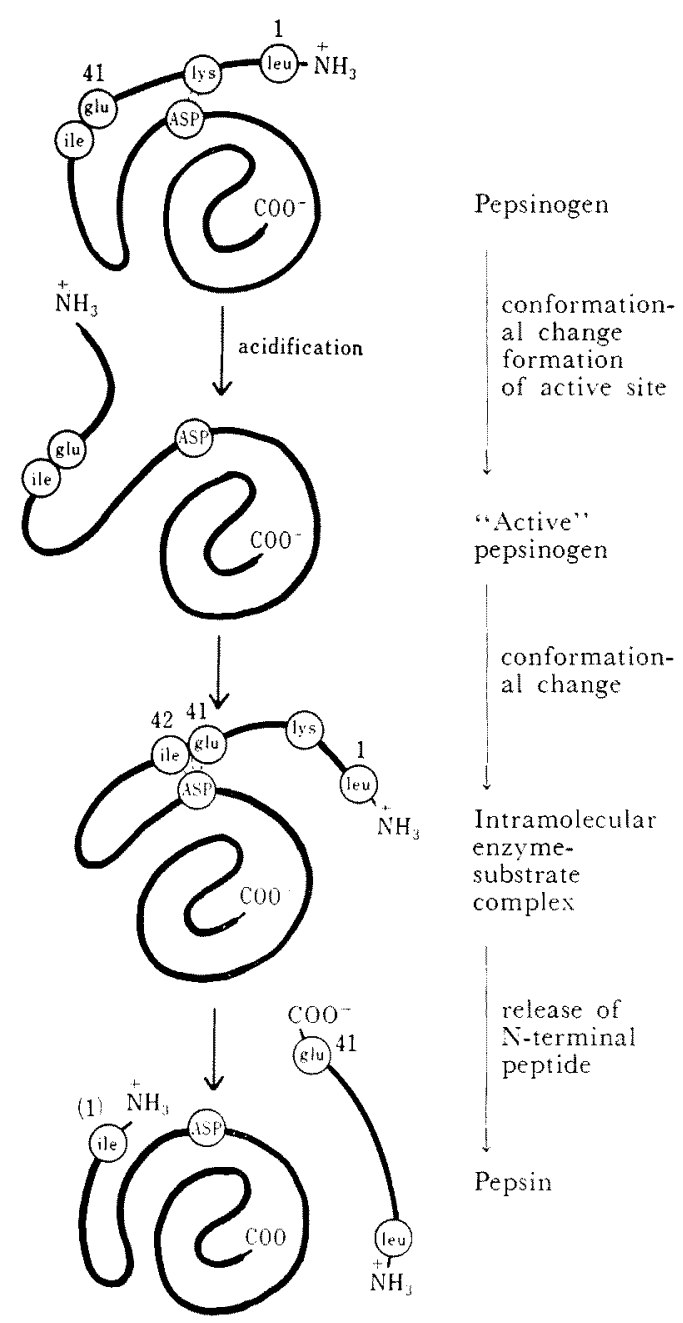

FIg. 4. A Schematic Diagram for the Activation Hypothesis of Pepsinogen.

Namely, pepsinogen is converted into "active" pepsinogen, which can interact with substrate or competitive inhibitor and exhibit peptic activity, without releasing N-terminal tail. Such a possibility was evidenced by the facts that the rate of appearance of activity was not affected by the presence of substrate or competitive inhibitor, while the rate of release of N-terminal isoleucine was affected by them. This assumption will be discussed 
again in the subsequent paper.

The second step is the hydrolysis of peptide bond between glytamyl and isoleucyl residues. The N-terminal tail of pepsinogen moves to a position in such a way that peptide bond of Glu-Ile locates in the juxta-position to the active site, forming an intramolecular enzymesubstrate complex. Thus, the bond is hydrolyzed by the catalysis of its own active site. The $\mathrm{N}$-terminal tail released from pepsinogen would be hydrolyzed by pepsin produced secondarily and resulted in the small peptides.

Acknowledgement. The authors wish to express their thanks to Professor B. Jirgensons, The University of Texas, M. D. Anderson Hospital and Tumor Institute at Houston, Texas Medical Center, for his valuable discussion for the preparation of this paper.

\section{REFERENCES}

1) M. Funatsu, Y. Harada, K. Hayashi and B. Jirgensons, Agr. Biol. Chem., 35, 566 (1971).

2) M. Bustin and A. Conway-Jacobs, J. Biol. Chem., 246, 615 (1971).

3) M. Heidelberger, ibid., 53, 31 (1922).
4) J.S. Fruton, M. Bergmann and W. P. Anslow, J. Biol. Chem., 127, 627 (1939).

5) J. Tang, ibid., 240, 3810 (1965).

6) idem, Nature, 199, 1094 (1963).

7) T. G. Rajagopalan, S. Moore and W. H. Stein, J. Biol. Chem., 241, 4940 (1966).

8) E. B. Ong and G. E. Perlmann, ibid., 243, 6104 (1968).

9) H. Neurath and G. H. Dixon, Fed. Proc., 16, 791 (1957).

10) M. Rovery, M. Poilroux, A. Yoshida and P. Desnuelle, Biochim. Biophys. Acta, 23, 608 (1957).

11) P. B. Sigler, D. M. Blow, B. W. Matthews and R. Henderson, J. Mol. Biol., 35, 143 (1968).

12) V.M. Stepanov and T. I. Vaganov. Izv. Akad. Nauk. USSR, Ser Kim., 12, 2785 (1967) [C.A., 69, 335n (1968)].

13) R. L. Lundbald and W. H. Stein, J. Biol. Chem., 244, $15 \neq$ (1969).

14) R. S. Bayliss and J. R. Knowles, Chem. Comm., 4, 196 (1968) [C.A., 69, 44159w (1968)].

15) L. V. Kozolov and V. N. Orekhovich, Biokimiya, 33, $15 \pm$ (1968) [C.A., 68, 102133s (1968)].

16) B. F. Erlanger, S. M. Vratsnanos, N. Wassermann and A. G. Cooper, Biochem. Biophys. Res. Commun., 28, 203 (1967). 